\title{
Periodic Breathing during Incremental Exercise
}

\author{
Piergiuseppe Agostoni ${ }^{1,2}$, Ugo Corrà ${ }^{3}$, and Michele Emdin ${ }^{4,5}$ \\ ${ }^{1}$ Centro Cardiologico Monzino, Istituto di Ricerca e Cura a Carattere Scientifico, Milan, Italy; ${ }^{2}$ Department of Clinical Sciences and \\ Community Health, Cardiovascular Section, University of Milan, Milan, Italy; ${ }^{3}$ Laboratory for the Analysis of Cardio-Respiratory Signals, \\ Istituti Clinici Scientifici Maugeri, IRCCS, Divisione di Cardiologia Riabilitativa, Veruno, Italy; ${ }^{4}$ Life Science Institute, Sant'Anna School of \\ Advanced Studies, Pisa, Italy; and ${ }^{5}$ Fondazione Toscana Gabriele Monasterio, Pisa, Italy
}

\begin{abstract}
Periodic breathing during incremental cardiopulmonary exercise testing is a regularly recurring waxing and waning of tidal volume due to oscillations in central respiratory drive. Periodic breathing is a sign of respiratory control system instability, which may occur at rest or during exercise. The possible mechanisms responsible for exertional periodic breathing might be related to any instability of the ventilatory regulation caused by: (1) increased circulatory delay (i.e., circulation time from the lung to the brain and chemoreceptors due to reduced cardiac index leading to delay in information transfer), (2) increase in controller gain (i.e., increased central and peripheral chemoreceptor sensitivity to arterial partial pressure of oxygen and of carbon dioxide), or (3) reduction in system damping (i.e., baroreflex impairment). Periodic breathing
\end{abstract}

during exercise is observed in several cardiovascular disease populations, but it is a particularly frequent phenomenon in heart failure due to systolic dysfunction. The detection of exertional periodic breathing is linked to outcome and heralds worse prognosis in heart failure, independently of the criteria adopted for its definition. In small heart failure cohorts, exertional periodic breathing has been abolished with several dedicated interventions, but results have not yet been confirmed.

Accordingly, further studies are needed to define the role of visceral feedbacks in determining periodic breathing during exercise as well as to look for specific tools for preventing/treating its occurrence in heart failure.

Keywords: periodic breathing; cardiopulmonary exercise testing; heart failure

(Received in original form January 2, 2017; accepted in final form April 24, 2017)

Correspondence and requests for reprints should be addressed to Ugo Corrà, M.D., Istituti Clinici Scientifici Maugeri, Via per Revislate, 13, 28010 Veruno (NO), Italy. E-mail: ugo.corra@icsmaugeri.it

Ann Am Thorac Soc Vol 14, Supplement 1, pp S116-S122, Jul 2017

Copyright (C) 2017 by the American Thoracic Society

DOI: 10.1513/AnnalsATS.201701-003FR

Internet address: www.atsjournals.org

Periodic breathing during incremental exercise is a regularly recurring waxing and waning of tidal volume due to oscillations in central respiratory drive (1); it is a sign of respiratory control system instability, which may also occur at rest before the exercise stimulation. Periodic breathing was first described two centuries ago $(2,3)$, and it is detected during exercise in normal subjects with a broad cardiovascular risk factor profile (4), in cardiovascular disease populations, and in patients who have undergone liver transplant and patients with anemia (1). Nonetheless, periodic breathing during exercise is above all recognized in patients with heart failure with depressed left ventricular ejection fraction (5-11). In these patients, periodic breathing can be observed at rest and during sleep (12), before exercise testing (13), and in awake patients (14), always having a prognostic value.

\section{An Example of Periodic Breathing during Exercise}

An example of periodic breathing during exercise in heart failure with depressed left ventricular ejection fraction is shown in Figure 1; it is characterized by cyclic variation of ventilation without interposed apnea. Typically, manual scoring or visual interpretation is used, and ventilation is the reference parameter derived from symptom-limited cardiopulmonary exercise testing (CPET), but other gas exchange variables do work and can be used in the assessment process. A programmed computerized analysis adopting period breathing during exercise criteria can facilitate its detection $(15,16)$; however, visual and manual scrutiny are performed in clinical routines (1). A diagram with broadened ventilation and time scales might be supportive to improve posttesting assessment, and no additional equipment is needed to detect periodic breathing during exercise.

Exercise-induced periodic breathing definitions were categorized in nine subsets, but only four refer to an original definition $(6,7,17,18)$; primary period breathing 


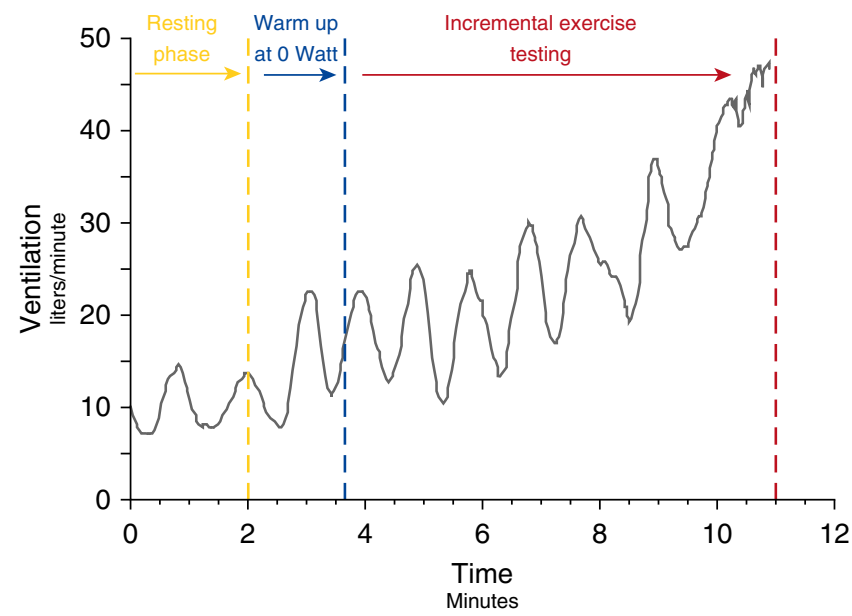

Figure 1. An example of periodic breathing during incremental exercise in chronic heart failure due to reduced left ventricular ejection fraction. $x$-Axis indicates time in minutes divided into three phases: 2-minute resting stage, 2-minute warm-up segment at $0 \mathrm{~W}$, and incremental exercise phase. Resting phase: minute ventilation measured during the resting phase, in sitting position. Warm up at 0 Watt: pedaling phase at $0 \mathrm{~W}$, anticipating the incremental exercise period. Incremental exercise testing: the exercise period on a bicycle. For patients with heart failure, a ramp protocol is used with $10-W$ increments every 1 minute. $y$-Axis: minute ventilation was measured during three phases. during exercise delineations are summarized in Table 1. Beyond the original period breathing during exercise definitions, other subdivisions were combinations of the original definitionsquantifications, computational, vaguely defined, or undefined (1). The American Heart Association recommends the definition, with the respiratory phenomenon lasting greater than or equal to $60 \%$ of the exercise phase and the amplitude of the single oscillation of greater modified Kremser periodic breathing than or equal to $15 \%$ of the resting averaged ventilation value (19).

Periodic breathing can be evanescent or transient. It has been observed in some only at rest, before starting the exercise test, or disappearing during the early stages of exercise (before the ventilator anaerobic threshold achievement), or indeed only disappearing at peak exercise in heart failure due to left ventricular dysfunction. Periodic breathing disappeared during exercise in $42 \%$ and remained through the entire exercise in $58 \%$ of the patients with heart
Table 1. Original definitions of periodic breathing during exercise in chronic heart failure due to left ventricular systolic dysfunction

Definition by Kremser and colleagues (17): Ventilatory oscillations lasting $\geqslant 66 \%$ of the exercise protocol, with an amplitude of each $\dot{V}_{E}$ oscillation $\geqslant 15 \%$ of the average value at rest

Definition by Leite and colleagues (6): Three or more regular $\dot{V}_{E}$ oscillations (i.e., clearly discernible from inherent data noise). Regularity was defined if the SD of three consecutive $V_{E}$ cycle lengths (time between two consecutive nadirs) was within $20 \%$ of the average; minimal average amplitude of $\dot{V}_{E}$ oscillation $\geqslant 5 L$ (peak value minus the average of two in-between consecutive nadirs)

Definition by Ben-Dov and colleagues (18): Marked $\dot{V}_{E}$ oscillations of 30-60 s duration. Magnitude $(\Delta) \dot{V}_{E}(\Delta=$ peak nadir/mean over the time period of the oscillation) $\geqslant 25 \%$ in two or more consecutive cycles (nadir to nadir) during exercise

Definition by Sun and colleagues (7): Three or more consecutive cyclic fluctuations of $\dot{V}_{\mathrm{E}}$ : amplitude of oscillatory $\dot{V}_{E} \geqslant 30 \%$ of concurrent mean $\dot{V}_{E}$ with a complete oscillatory cycle within 40-140 s. VE oscillations of similar frequency must also be visible in three or more of the following variables: oxygen pulse, $\dot{\mathrm{V}}_{2}, \dot{\mathrm{V}}_{\mathrm{CO}_{2}}, \dot{\mathrm{V}} \mathrm{E} / \mathrm{V}_{\mathrm{CO}_{2}}, \mathrm{RER}, \mathrm{PET}_{\mathrm{O}_{2}}$, or $\mathrm{PET}_{\mathrm{CO}_{2}}$

Definition of abbreviations: $\mathrm{PET}_{\mathrm{O}_{2}}=$ oxygen end-tidal pressure, $\mathrm{PET}_{\mathrm{CO}_{2}}=$ carbon dioxide end-tidal pressure; RER = respiratory gas exchange ratio (i.e., $\dot{\mathrm{V}} \mathrm{CO}_{2} \dot{\mathrm{N}_{2}}$ ). failure (20), but gas exchange response is almost similar.

\section{Mechanisms of Period Breathing during Exercise in Heart Failure due to Left Ventricular Dysfunction}

The primary purpose of the lung is to maintain the arterial partial pressure of oxygen and carbon dioxide near normal resting levels. During exercise, this is challenged because (1) oxygenation of the mixed venous blood delivered to the lungs is reduced greatly; (2) a fourfold increase in cardiac output causes a reduction in pulmonary capillary transit time, thus decreased time, for complete equilibration of oxygen between alveoli and pulmonary capillaries; (3) the lung receives all of the cardiac output, so it has to adapt to maintain low vascular pressures and protect against exudation of plasma water into the alveoli; and (4) there is a 20 -fold increase in minute ventilation to meet the increased metabolic demand, which necessitates a need for efficiency in breathing. The control of the normal ventilation is through the feedback loop between pulmonary gasexchanging capillaries and peripheral chemoreceptors located in the carotid bodies and the central chemoreceptors located in the medulla.

Any instability of ventilatory regulation can lead to generation of periodic breathing. There are data regarding the mechanistic basis of periodic breathing (21-33), but, although the underlying mechanism of periodic breathing at rest and during the night in heart failure is somehow similar to that presumed for exercise-induced periodic breathing $(26,27,32,33)$, the underlying mechanism of exercise-induced periodic breathing is not the same. Instinctively, an exercise-induced stimulus may operate differently on central and peripheral hemodynamics and control respiratory systems. However, and of note, both exercise-induced periodic breathing and nocturnal apneas/hypopneas are significantly reduced by increasing cardiac output in patients with heart failure with left ventricular assist devices (34).

Performing a quantitative algebraic analysis of exertional periodic breathing, it was found that the principal physiological factors are circulatory delay and an increased chemoreflex gain (30), and the 
inspiration of oxygen evokes a decrease in chemosensitivity and abolishes the periodic breathing pattern (30). Up until now, studies explaining the possible pathophysiology of exercise-induced period breathing suggest that it can be generated by: (1) increased circulatory delay, (2) increase in controller gain, or (3) reduction in system damping (i.e., baroreflex impairment). Potential and promising mechanisms are summarized in Table 2.

As the pathophysiology of exerciseinduced period breathing is not fully understood, adequate therapy is challenging.

\section{Prevalence of Periodic Breathing during Exercise in Heart Failure due to Left Ventricular Dysfunction}

CPET provides a unique opportunity to evaluate aerobic capacity with breath-bybreath expired gas parameters $(19,35)$, and several CPET-derived parameters have been shown to be linked to outcome (36) in addition to peak oxygen consumption $\left(\dot{\mathrm{V}}_{2}\right)$ and ventilatory efficiency $\left(\dot{\mathrm{V}} / \dot{\mathrm{V}}_{\mathrm{CO}_{2}}\right.$ slope). Periodic breathing is discerned during submaximal exercise (35), which makes it an attractive parameter in those patients who are not able to complete maximal effort exercise testing.

In 2015 , a systematic review screened 75 studies, accounting for 17,440 patients, of whom 4,638 (26.6\%) presented periodic breathing during exercise (1). Due to lack of a uniformly accepted description of periodic breathing during exercise, the appropriate occurrence of this abnormal breathing phenomenon is precluded. Periodic breathing prevalence was $25 \%$ using the Corrà method and $31 \%$ using the
Leite method (37). In limited heart failure cohorts, the prevalence of periodic breathing during exercise ranges from 6 to $58 \%(5-10,22,30,33,38)$, whereas in a study of $\sim 6,000$ patients with heart failure on behalf of the Metabolic Exercise, Cardiac, Kidney Index (MECKI) score research group $(39,40)$, exercise-induced periodic breathing was present in $17.5 \%$, and it is especially observed in those with the most impaired exercise capacity and in women (41), in agreement with what is observed in normal subjects (4).

\section{Characteristics of Patients with Heart Failure with Periodic Breathing during Exercise}

Most selection criteria and study prerequisites are chaotic but fairly comparable, and they contribute to misperceptions about the clinical characteristics of patients with heart failure with exercise-induced periodic breathing. Patients with periodic breathing are, on average, older, have an advanced New York Heart Association class, and show a lower percentage of ischemic etiology of heart failure (1) and treatment with $\beta$-blockers (9). Mean left ventricular ejection fraction is lower (1), and left atrial dimension, mitral E-wave velocity, and right heart pressures are increased (42). Median exercise duration is shorter, peak $\dot{\mathrm{V}}_{2}$ is lower, $\dot{\mathrm{V}} / \dot{\mathrm{V}}_{\mathrm{CO}_{2}}$ slope is higher $(1,5-9)$, rest and exercise end-tidal carbon dioxide are reduced, and an increased ventilatory equivalent for carbon dioxide and dead space ventilation is witnessed (42). Peak respiratory gas exchange ratio is similar between patients with or without periodic breathing during exercise $(5-7,10,37)$.

Table 2. Plausible mechanisms of periodic breathing during exercise in chronic heart failure due to left ventricular systolic dysfunction

Circulatory delay: prolonged circulation time from the lung to the brain and chemoreceptors leading to delay in information transfer

Reduced cardiac output

Hemodynamic impairment both at rest and during exercise.

Increased chemosensitivity: increased central and peripheral chemoreceptor sensitivity to arterial partial pressure of oxygen and carbon dioxide, leading to:

Increased sympathetic overactivity

Enhanced hypoxic and central hypercapnic chemosensitivity

Nonperipheral chemoreceptor-mediated mechanisms

Pulmonary congestion

Ergoreflex signaling

Hence, on average, periodic breathing is associated with a more advanced cardiovascular disease condition, reduced left ventricular ejection fraction, advanced New York Heart Association class, impaired hemodynamic response to exercise, and reduced aerobic capacity, together with higher ventilation in heart failure due to reduced left ventricular ejection fraction.

\section{Cost of Breathing of Periodic Breathing during Exercise in Heart Failure}

Energy expenditure at rest requires an oxygen uptake in the range between 160 and $290 \mathrm{ml} / \mathrm{min}$ or approximately $3.5 \mathrm{ml} / \mathrm{kg} / \mathrm{min}$ ( 1 metabolic equivalent; oxygen consumed while seated at rest), depending on such factors as sex, age, body size, and fat-free body mass. Any physical activity performed increases oxygen consumption. Periodic breathing during exercise is likely to increase the respiratory muscles' work, and those with periodic breathing during exercise and at peak exercise show a less efficient ventilatory pattern, which suggests a greater respiratory muscle work and therefore a greater respiration-related $\dot{\mathrm{V}}_{2}(20)$. The presence of periodic breathing negatively influences exercise performance, and periodic breathing disappearance during exercise allows, in some cases, a more efficient exercise performance.

\section{Prognostic Value of Periodic Breathing during Exercise in Heart Failure with Left Ventricular Dysfunction}

Despite a paucity of large-scale studies, there is compelling evidence that periodic breathing during exercise is a strong independent prognosticator in heart failure with left ventricular dysfunction (5-11, 37, 42-46). Periodic breathing during exercise is related to higher risk of events in the whole spectrum of heart failure with left ventricular dysfunction $(5,8)$, in heart transplantation candidates (6), and in patients chronically treated with $\beta$-blockers (9). Moreover, exerciseinduced periodic breathing predicts sudden death (10), and it is connected with short-term morbidity and mortality (7). 
The definition of periodic breathing during exercise affects the number of patients with heart failure diagnosed and their outcome; although patients with heart failure with exercise-induced periodic breathing observed with Corrá and Leite methods showed higher risk than for peak $\dot{\mathrm{V}}_{2}$ or $\dot{\mathrm{V}} \mathrm{E} / \dot{\mathrm{V}}_{\mathrm{CO}_{2}}$ slope, Kaplan-Meier curves show a larger separation between patient groups using the Corrà method (37). Table 3 summarizes available prognostic periodic breathing during exercise studies in heart failure; those habitually treated with $\beta$-blockers are also listed, as periodic breathing during exercise is less frequent in this setting.

The 2008 European Society of Cardiology Guidelines for the diagnosis and treatment of acute and chronic heart failure (47) acknowledged exerciseinduced periodic breathing as a powerful risk parameter derived from symptomlimited cardiopulmonary exercise testing, together with peak $\dot{\mathrm{V}}_{2}$ and $\dot{\mathrm{V}} / \dot{\mathrm{V}}_{\mathrm{CO}_{2}}$ slope. The 2008 European Society of Cardiology predictive model (including periodic breathing during exercise, peak $\dot{\mathrm{V}}_{2}$, and $\dot{\mathrm{V}}_{\mathrm{E}} / \dot{\mathrm{V}}_{\mathrm{CO}_{2}}$ slope) was validated in heart failure due to left ventricular dysfunction. The 2008 European Society of Cardiology predictive model prognostic performance was not altered by the addition of other supplementary risk CPET parameters except for peak systolic blood pressure (48).

Table 3. Studies that have shown a prognostic impact of periodic breathing during exercise in chronic heart failure due to left ventricular systolic dysfunction

\begin{tabular}{|c|c|c|c|c|c|c|c|}
\hline Study & $\begin{array}{l}\text { No. of } \\
\text { Patients }\end{array}$ & $\begin{array}{l}\text { Mean NYHA } \\
\text { and LVEF }\end{array}$ & 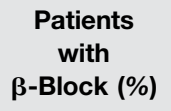 & $\begin{array}{l}\text { Patients } \\
\text { with } \\
\text { PB (\%) }\end{array}$ & $\begin{array}{c}\text { PB } \\
\text { Definition }\end{array}$ & $\begin{array}{l}\text { Events during } \\
\text { Follow-up }\end{array}$ & $\begin{array}{l}\text { Statistical Relationship } \\
\text { between PB Occurrence } \\
\text { and Prognosis }\end{array}$ \\
\hline $\begin{array}{l}\text { Corrà and } \\
\text { colleagues, } \\
2002(5)\end{array}$ & 323 & $\begin{array}{l}\text { NYHA } 2.2 \pm 0.9 \\
\text { LVEF } 24 \pm 8 \%\end{array}$ & 37 & 11.8 & Kremser & $\begin{array}{l}\text { CV mortality, } \\
\text { urgent HXT }\end{array}$ & $\begin{array}{l}\text { PB present in } 28 \% \text { of } \\
\text { nonsurvivors. HR of PB is } \\
10.5(P<0.0001) \text { at MTV }\end{array}$ \\
\hline $\begin{array}{l}\text { Leite and } \\
\text { colleagues, } \\
2003(6)\end{array}$ & 84 & $\begin{array}{l}\text { NYHA 2-4, } \\
\text { LVEF } 35 \pm 7 \%\end{array}$ & NA & 29.4 & Leite & $\begin{array}{l}\text { All-cause } \\
\text { mortality }\end{array}$ & $\begin{array}{l}\text { PB increased the risk of } \\
\text { death by } 2.97 \text {-fold } \\
(P=0.007) \text { with } 95 \% \mathrm{Cl} \text {, } \\
1.34-6.54\end{array}$ \\
\hline $\begin{array}{l}\text { Corrà and } \\
\text { colleagues, } \\
2006 \text { (60) }\end{array}$ & 133 & $\begin{array}{l}\text { NYHA } 2.3 \pm 0.7 \\
\text { LVEF } 23 \pm 7 \%\end{array}$ & 46 & 21.1 & Kremser & $\begin{array}{l}\text { CV mortality, } \\
\text { urgent HXT }\end{array}$ & $\begin{array}{l}\text { CV mortality } 46 \text { and } 17 \% \\
(P<0.01) \text { in those with } \\
\text { and without PB. PB is not } \\
\text { selected at MTV including } \\
\text { CSA alone and combined } \\
\text { CSA }\end{array}$ \\
\hline $\begin{array}{l}\text { Guazzi and } \\
\text { colleagues, } \\
2007 \text { (8) }\end{array}$ & 288 & $\begin{array}{l}\text { NYHA } 2.1 \pm 0.8, \\
\text { LVEF } 33 \pm 13 \%\end{array}$ & 57 & 35 & Leite & CV mortality & $\begin{array}{l}\text { HR of PB } 5.5(P<0.0001) \\
\text { with a } 95 \% \mathrm{Cl}, 3.2-9.5 \text { at } \\
\text { MTV }\end{array}$ \\
\hline $\begin{array}{l}\text { Guazzi and } \\
\text { colleagues, } \\
2007 \text { (10) }\end{array}$ & 153 & $\begin{array}{l}\text { NYHA 1-4, } \\
\text { LVEF } 35 \pm 11 \%\end{array}$ & 52 & 35.1 & Leite & Sudden death & $\begin{array}{l}\text { HR of PB is } 7.9 \text { (with } 95 \% \mathrm{Cl} \text {, } \\
3.7-17 \text { ) for all cardiac } \\
\text { mortality and } 45.4(6-34.3 \text { ) } \\
\text { for SD (both } P<0.0001 \text { ) at } \\
\text { UTV }\end{array}$ \\
\hline $\begin{array}{l}\text { Arena and } \\
\text { colleagues, } \\
2008(45)\end{array}$ & 154 & $\begin{array}{l}\text { NYHA } 2.2, \\
\text { LVEF } 30 \pm 14 \%\end{array}$ & 60 & 35.7 & Kremser & $\begin{array}{l}\mathrm{HXT}, \mathrm{LVAD}, \mathrm{CV} \\
\text { mortality }\end{array}$ & $\begin{array}{l}\text { Event-free survival } 55 \% \text { in } \\
\text { PB. } \chi^{2} \text { of PB was } 10.2 \\
(P<0.0001) \text { at MTV }\end{array}$ \\
\hline $\begin{array}{l}\text { Ingle and } \\
\text { colleagues, } \\
2009 \text { (37) }\end{array}$ & 240 & LVEF $34 \pm 6 \%$ & 61 & $\begin{array}{l}31 \text { Leite } \\
25 \text { Corrà }\end{array}$ & Leite/Corrà & $\begin{array}{l}\text { All-cause } \\
\text { mortality }\end{array}$ & $\begin{array}{l}\mathrm{HR} \text { of } \mathrm{PB} \text { is } 5.2(95 \% \mathrm{Cl}, \\
2.8-9.6) \text { for Corrà and } 4.8 \\
(95 \% \mathrm{Cl}, 2.6-8.8) \text { for Leite } \\
\text { method (both } P<0.0001) \\
\text { at UTV; at MTV, only Corrà } \\
\text { method is selected, with } \\
\text { an HR of } 6.3(95 \% \mathrm{Cl}, \\
1.6-25.2)\end{array}$ \\
\hline $\begin{array}{l}\text { Corrà and } \\
\text { colleagues, } \\
2009 \text { (9) }\end{array}$ & 631 & $\begin{array}{l}\text { NYHA } 1.9 \pm 0.6 \\
\text { LVEF } 29 \pm 8 \%\end{array}$ & 100 & 7 & Kremser & $\begin{array}{l}\text { CV mortality, } \\
\text { urgent HXT }\end{array}$ & $\begin{array}{l}\mathrm{HR} \text { of } \mathrm{PB} \text { is } 4.3 \text { with } 95 \% \mathrm{Cl} \text {, } \\
2.5-7.4(P<0.0001) \text { at } \\
\text { MTV }\end{array}$ \\
\hline $\begin{array}{l}\text { Guazzi and } \\
\text { colleagues, } 2010 \\
\text { (PROBE study) (44) }\end{array}$ & 695 & $\begin{array}{l}\text { NYHA } 2.4 \pm 0.7 \\
\quad \text { LVEF } 25.6 \pm 8 \%\end{array}$ & 73 & 36 & Leite & CV mortality & $\begin{array}{l}\mathrm{HR} \text { of } \mathrm{PB} \text { is } 2.2(P<0.0001) \\
\text { with } 95 \% \mathrm{Cl}, 1.6-3.2 \text { at } \\
\text { MTV }\end{array}$ \\
\hline $\begin{array}{l}\text { Sun and colleagues, } \\
2010(7)\end{array}$ & 580 & $\begin{array}{l}\text { NYHA 2-4, } \\
\text { LVEF } 26 \pm 7 \%\end{array}$ & NA & 51 & Sun & $\begin{array}{l}\text { 6-mo mortality } \\
\text { and morbidity }\end{array}$ & $\begin{array}{l}\text { Mean OR increase for } \\
\text { mortality (range, } 12.7- \\
39.8 \text { ) and morbidity (2.5- } \\
\text { 3.9) if PB was added to } \\
\text { CPET risk parameters }\end{array}$ \\
\hline $\begin{array}{l}\text { Scardovi and } \\
\text { colleagues, } \\
2012(46)\end{array}$ & $370(\geqslant 65 \mathrm{yr})$ & $\begin{array}{l}\text { NYHA 1-3, } \\
\text { LVEF } 41 \%\end{array}$ & 61 & 58 & Leite & $\begin{array}{l}\text { All-cause } \\
\text { mortality, } \\
\text { Combined end } \\
\text { points }\end{array}$ & $\begin{array}{l}\mathrm{HR} \text { of } \mathrm{PB} \text { is } 8.9(P<0.0001 \\
\text { with } 95 \% \mathrm{Cl}, 1.4-4.9) \text { at } \\
\text { MTV }\end{array}$ \\
\hline
\end{tabular}

Definition of abbreviations: $\beta$-Block = $\beta$-blockers; $\mathrm{Cl}=$ confidence interval; combined $\mathrm{CSA}=\mathrm{CSA}$ with PB or elevated $\dot{\mathrm{V}}_{\mathrm{E}} \dot{\mathrm{V}} \mathrm{CO}_{2}$ slope $(>33)$; CPET = cardiopulmonary exercise testing; CSA = central sleep apnea; $C V=$ cardiovascular; HR = hazard ratio; HXT = heart transplantation; LVAD = left ventricular assistance device implantation; LVEF = left ventricular ejection fraction; MTV = multivariable Cox regression analysis; NA = not available; NYHA = New York Heart Association class; $\mathrm{OR}=$ odds ratio; $\mathrm{PB}=$ periodic breathing; UTV = univariate Cox regression analysis.

Data are presented as average, mean, or range. 


\section{The Occurrence and Prognostic Consequence of Exercise-induced Periodic Breathing in Heart Failure with Preserved Ejection Fraction}

The diagnosis of heart failure with preserved left ventricular ejection fraction is challenging (49), as its pathophysiology is heterogeneous and it is associated with different concomitant cardiovascular diseases (e.g., atrial fibrillation, arterial hypertension, coronary artery disease, pulmonary hypertension) and noncardiovascular diseases (diabetes, chronic kidney disease, anemia, iron deficiency, chronic obstructive pulmonary disease, and obesity). Functional intolerance is the primary symptom in heart failure with preserved left ventricular ejection fraction (50).

Periodic breathing during exercise is detected either in $31 \%$ (51) or in $7 \%$ (52) of patients with heart failure with preserved left ventricular ejection fraction, and the difference lies either in patients' enrollment criteria or in periodic breathing delineations. In some experiences, peak $\dot{\mathrm{V}}_{2}, \dot{\mathrm{V}} \mathrm{E} / \dot{\mathrm{V}}_{\mathrm{CO}_{2}}$ slope, and exercise-induced periodic breathing preserve their predictive power $(51,53)$, whereas, according to the
Henry Ford Hospital Cardiopulmonary Exercise Testing (FIT-CPX) project, peak $\dot{\mathrm{V}}_{2}$ and percentage of predicted peak $\dot{\mathrm{V}}_{2}$ are linked to outcome but not periodic breathing during exercise (52).

\section{Reversibility of Periodic Breathing during Exercise}

Periodic breathing during exercise is reproducible (7). Various pharmacological or surgical interventions have been performed in chronic heart failure due to left ventricular dysfunction to identify the reversibility of this respiratory exerciseinduced phenomenon (53-59): heart transplantation, inotropic drugs, continuous positive airway pressure, adaptive servo ventilation, and exercise training might all impact occurrence of periodic breathing during exercise.

Although large-scale clinical trials with periodic breathing vanishing as the primary endpoint are not available yet, these data are fascinating, as revocation of a risk factor such as exercise-induced periodic breathing in heart failure is provocative and motivating. Up to now, it is not clear if a positive response to intervention is abolishing of exercise-induced periodic breathing or reduction of the duration of the respiratory phenomenon/amplitude of single ventilation oscillations.

\section{Conclusions}

Periodic breathing during exercise is a frequent phenomenon in patients with heart failure, heralding a poor outcome independently of an optimized medical treatment. Its pathophysiology probably shares some mechanisms of Cheyne-Stoke respiration and central sleep apnea, but periodic breathing during exercise and central sleep apnea have independent prognostic value in heart failure due to left ventricular dysfunction (60), pointing out that exercise, per se, is able to trigger periodic breathing in patients prone to abnormal breathing patterns. Further studies are needed to define the role of visceral feedback in determining periodic breathing either at rest or during exercise as well as to look for specific tools for preventing its occurrence, which may be seen as a marker of clinical severity and of prognosis in patients with heart failure.

Author disclosures are available with the text of this article at www.atsjournals.org.

\section{References}

1 Cornelis J, Beckers P, Vanroy C, Volckaerts T, Vrints C, Vissers D. An overview of the applied definitions and diagnostic methods to assess exercise oscillatory ventilation-a systematic review. Int J Cardiol 2015:190:161-169.

2 Cheyne J. A case of apoplexy in which the fleshy part of the heart was converted in fat. Dublin Hosp Rep 1818;2:216-219.

3 Stokes W. The disease of the heart and aorta. Dublin: Hodges and Smith, 1854.

4 Guazzi M, Arena R, Pellegrino M, Bandera F, Generati G, Labate V, Alfonzetti E, Villani S, Gaeta MM, Halle M, et al. Prevalence and characterization of exercise oscillatory ventilation in apparently healthy individuals at variable risk for cardiovascular disease: a subanalysis of the EURO-EX trial. Eur J Prev Cardiol 2016;23: 328-334.

5 Corrà U, Giordano A, Bosimini E, Mezzani A, Piepoli M, Coats AJ, Giannuzzi $P$. Oscillatory ventilation during exercise in patients with chronic heart failure: clinical correlates and prognostic implications. Chest 2002;121:1572-1580.

6 Leite JJ, Mansur AJ, de Freitas HF, Chizola PR, Bocchi EA, Terra-Filho M Neder JA, Lorenzi-Filho G. Periodic breathing during incremental exercise predicts mortality in patients with chronic heart failure evaluated for cardiac transplantation. J Am Coll Cardiol 2003;41: 2175-2181.

7 Sun XG, Hansen JE, Beshai JF, Wasserman K. Oscillatory breathing and exercise gas exchange abnormalities prognosticate early mortality and morbidity in heart failure. J Am Coll Cardiol 2010;55: 1814-1823.

8 Guazzi M, Arena R, Ascione A, Piepoli M, Guazzi MD; Gruppo di Studio Fisiologia dell'Esercizio, Cardiologia dello Sport e Riabilitazione
Cardiovascolare of the Italian Society of Cardiology. Exercise oscillatory breathing and increased ventilation to carbon dioxide production slope in heart failure: an unfavorable combination with high prognostic value. Am Heart J 2007;153:859-867.

9 Corrà U, Mezzani A, Giordano A, Bosimini E, Giannuzzi P. Exercise hemodynamic variables rather than ventilatory efficiency indexes contribute to risk assessment in chronic heart failure patients treated with carvedilol. Eur Heart J 2009;27:684-690.

10 Guazzi M, Raimondo R, Vicenzi M, Arena R, Proserpio C, Sarzi Braga S Pedretti R. Exercise oscillatory ventilation may predict sudden cardiac death in heart failure patients. J Am Coll Cardiol 2007;50: 299-308.

11 Agostoni P, Corrà U, Cattadori G, Veglia F, La Gioia R, Scardovi AB, Emdin M, Metra M, Sinagra G, Limongelli G, et al.; MECKI Score Research Group. Metabolic exercise test data combined with cardiac and kidney indexes, the MECKI score: a multiparametric approach to heart failure prognosis. Int J Cardiol 2013;167:2710-2718.

12 Lanfranchi PA, Braghiroli A, Bosimini E, Mazzuero G, Colombo R, Donner CF, Giannuzzi P. Prognostic value of nocturnal CheyneStokes respiration in chronic heart failure. Circulation 1999;99: 1435-1440.

13 Feld $\mathrm{H}$, Priest $\mathrm{S}$. A cyclic breathing pattern in patients with poor left ventricular function and compensated heart failure: a mild form of Cheyne-Stokes respiration? J Am Coll Cardiol 1993;21:971-974.

14 Poletti R, Passino C, Giannoni A, Zyw L, Prontera C, Bramanti F, Clerico A, Piepoli M, Emdin M. Risk factors and prognostic value of daytime Cheyne-Stokes respiration in chronic heart failure patients. Int J Cardiol 2009;137:47-53.

15 Olson TP, Johnson BD. Quantifying oscillatory ventilation during exercise in patients with heart failure. Respir Physiol Neurobiol 2014; 190:25-32. 
16 Cornelis J, Denis T, Beckers P, Vrints C, Visser D, Gossens M. Development of a clinical applicable graphical user interface to automatically detect exercise oscillatory ventilation: the VOdEX-tool. Int J Cardiol [online ahead of print] 29 Dec 2016; DOI: 10.1016/j. ijcard.2016.12.159.

17 Kremser CB, O'Toole MF, Leff AR. Oscillatory hyperventilation in severe congestive heart failure secondary to idiopathic dilated cardiomyopathy or to ischemic cardiomyopathy. Am J Cardiol 1987; 59:900-905.

18 Ben-Dov I, Sietsema KE, Casaburi R, Wasserman K. Evidence that circulatory oscillations accompany ventilatory oscillations during exercise in patients with heart failure. Am Rev Respir Dis 1992;145: 776-781.

19 Balady GJ, Arena R, Sietsema K, Myers J, Coke L, Fletcher GF, Forman D, Franklin B, Guazzi M, Gulati M, et al.; American Heart Association Exercise, Cardiac Rehabilitation, and Prevention Committee of the Council on Clinical Cardiology; Council on Epidemiology and Prevention; Council on Peripheral Vascular Disease; Interdisciplinary Council on Quality of Care and Outcomes Research. Clinician's Guide to cardiopulmonary exercise testing in adults: a scientific statement from the American Heart Association. Circulation 2010;122:191-225.

20 Schmid JP, Apostolo A, Antonioli L, Cattadori G, Zurek M, Contini M, Agostoni $P$. Influence of exertional oscillatory ventilation on exercise performance in heart failure. Eur J Cardiovasc Prev Rehabil 2008;15: 688-692.

21 Piepoli MF, Ponikowski PP, Volterrani M, Francis D, Coats AJ. Aetiology and pathophysiological implications of oscillatory ventilation at rest and during exercise in chronic heart failure: do Cheyne and Stokes have an important message for modern-day patients with heart failure? Eur Heart $J$ 1999;20:946-953.

22 Murphy RM, Shah RV, Malhotra R, Pappagianopoulos PP, Hough SS, Systrom DM, Semigran MJ, Lewis GD. Exercise oscillatory ventilation in systolic heart failure: an indicator of impaired hemodynamic response to exercise. Circulation 2011;124: 1442-1451.

23 Dhakal BP, Murphy RM, Lewis GD. Exercise oscillatory ventilation in heart failure. Trends Cardiovasc Med 2012;22:185-191.

24 Dhakal BP, Lewis GD. Exercise oscillatory ventilation: mechanisms and prognostic significance. World J Cardiol 2016;8:258-266.

25 Cherniack NS, Longobardo GS. Cheyne-Stokes breathing: an instability in physiologic control. N Engl J Med 1973;288: 952-957.

26 Ponikowski P, Anker SD, Chua TP, Francis D, Banasiak W, PooleWilson PA, Coats AJ, Piepoli M. Oscillatory breathing patterns during wakefulness in patients with chronic heart failure: clinical implications and role of augmented peripheral chemosensitivity. Circulation 1999;100:2418-2424.

27 Yajima T, Koike A, Sugimoto K, Miyahara Y, Marumo F, Hiroe M. Mechanism of periodic breathing in patients with cardiovascular disease. Chest 1994;106:142-146.

28 Agostoni P, Apostolo A, Albert RK. Mechanisms of periodic breathing during exercise in patients with chronic heart failure. Chest 2008;133: 197-203.

29 Giannoni A, Emdin M, Bramanti F, ludice G, Francis DP, Barsotti A, Piepoli M, Passino C. Combined increased chemosensitivity to hypoxia and hypercapnia as a prognosticator in heart failure. $\mathrm{J} \mathrm{Am}$ Coll Cardiol 2009;53:1975-1980.

30 Francis DP, Willson K, Davies LC, Coats AJ, Piepoli M. Quantitative general theory for periodic breathing in chronic heart failure and its clinical implications. Circulation 2000;102:2214-2221.

31 Chua TP, Clark AL, Amadi AA, Coats AJ. Relation between chemosensitivity and the ventilatory response to exercise in chronic heart failure. J Am Coll Cardiol 1996;27:650-657.

32 Hanly P, Zuberi N, Gray R. Pathogenesis of Cheyne-Stokes respiration in patients with congestive heart failure: relationship to arterial PCO2. Chest 1993;104:1079-1084.

33 Ponikowski PP, Chua TP, Francis DP, Capucci A, Coats AJ, Piepoli MF. Muscle ergoreceptor overactivity reflects deterioration in clinical status and cardiorespiratory reflex control in chronic heart failure. Circulation 2001;104:2324-2330.
34 Agostoni P, Contini M, Vignati C, Del Torto A, De Vecchi Lajolo G, Salvioni E, Spadafora E, Lombardi C, Gerosa G, Bottio T, et al. Acute increase of cardiac output reduces central sleep apneas in heart failure patients. J Am Coll Cardiol 2015;66:2571-2572.

35 Mezzani A, Agostoni $P$, Cohen-Solal $A$, Corrà U, Jegier A, Kouidi E, Mazic S, Meurin P, Piepoli M, Simon A, et al. Standards for the use of cardiopulmonary exercise testing for the functional evaluation of cardiac patients: a report from the Exercise Physiology Section of the European Association for Cardiovascular Prevention and Rehabilitation. Eur J Cardiovasc Prev Rehabil 2009;16:249-267.

36 Corrà U, Piepoli MF, Adamopoulos S, Agostoni P, Coats AJS, Conraads V, Lambrinou E, Pieske B, Piotrowicz E, Schmid J-P, et al. Cardiopulmonary exercise testing in systolic heart failure in 2014: the evolving prognostic role: a position paper from the committee on exercise physiology and training of the heart failure association of the ESC. Eur J Heart Fail 2014;16:929-941.

37 Ingle L, Isted A, Witte KK, Cleland JG, Clark AL. Impact of different diagnostic criteria on the prevalence and prognostic significance of exertional oscillatory ventilation in patients with chronic heart failure. Eur J Cardiovasc Prev Rehabil 2009;16:451-456.

38 Matsuki R, Kisaka T, Ozono R, Kinoshita H, Sada Y, Oda N, Hidaka T, Tashiro N, Takahashi M, Sekikawa K, et al. Characteristics of patients with severe heart failure exhibiting exercise oscillatory ventilation. Clin Exp Hypertens 2013;35:267-272.

39 Carubelli V, Metra M, Corrà U, Magrì D, Passino C, Lombardi C, Scrutinio D, Correale M, Cattadori G, Piepoli MF, et al.; MECKI score research group. Exercise performance is a prognostic indicator in elderly patients with chronic heart failure - application of metabolic exercise cardiac kidney indexes score. Circ J 2015;79: 2608-2615.

40 Scrutinio D, Agostoni P, Gesualdo L, Corrà U, Mezzani A, Piepoli M, Di Lenarda A, lorio A, Passino C, Magri D, et al.; Metabolic Exercise test data combined with Cardiac and Kidney Indexes (MECKI) Score Research Group. Renal function and peak exercise oxygen consumption in chronic heart failure with reduced left ventricular ejection fraction. Circ J 2015;79:583-591.

41 Agostoni PG, Apostolo A, Corrà U. Exertional oscillatory ventilation and central sleep apnea in heart failure: siblings, cousins, or what else? In: Emdin M, Giannoni A, Passino C, editors. The breathless heart: apneas in heart failure. Springer; 2017. pp. 183-202.

42 Olson LJ, Arruda-Olson AM, Somers VK, Scott CG, Johnson BD. Exercise oscillatory ventilation: instability of breathing control associated with advanced heart failure. Chest 2008;133:474-481.

43 Cornelis J, Taeymans J, Hens W, Beckers P, Vrints C, Vissers D. Prognostic respiratory parameters in heart failure patients with and without exercise oscillatory ventilation - a systematic review and descriptive meta-analysis. Int J Cardiol 2015;182:476-486.

44 Guazzi M, Boracchi P, Arena R, Myers J, Vicenzi M, Peberdy MA, Bensimhon D, Chase P, Reina G. Development of a cardiopulmonary exercise prognostic score for optimizing risk stratification in heart failure: the $(\mathrm{P}) \mathrm{e}(\mathrm{R}) \mathrm{i}(\mathrm{O}) \mathrm{dic}(\mathrm{B})$ reathing during $(\mathrm{E})$ xercise $(\mathrm{PROBE})$ study. $\checkmark$ Card Fail 2010;16:799-805.

45 Arena R, Myers J, Abella J, Peberdy MA, Pinkstaff S, Bensimhon D, Chase P, Guazzi M. Prognostic value of timing and duration characteristics of exercise oscillatory ventilation in patients with heart failure. J Heart Lung Transplant 2008;27:341-347.

46 Scardovi AB, De Maria R, Ferraironi A, Gatto L, Celestini A, Forte S, Parolini M, Sciarretta S, Ricci R, Guazzi M. A case for assessment of oscillatory breathing during cardiopulmonary exercise test in risk stratification of elderly patients with chronic heart failure. Int J Cardiol 2012;155:115-119.

47 Dickstein K, Cohen-Solal A, Filippatos G, McMurray JJV, Ponikowski P, Poole-Wilson PA, Strömberg A, van Veldhuisen DJ, Atar D, Hoes AW, et al.; ESC Committee for Practice Guidelines (CPG). ESC guidelines for the diagnosis and treatment of acute and chronic heart failure 2008: the Task Force for the diagnosis and treatment of acute and chronic heart failure 2008 of the European Society of Cardiology. Eur Heart $J$ 2008;29:2388-2442.

48 Corrà U, Giordano A, Mezzani A, Gnemmi M, Pistono M, Caruso R, Giannuzzi P. Cardiopulmonary exercise testing and prognosis in heart failure due to systolic left ventricular dysfunction: a validation study of the European Society of Cardiology Guidelines and 
Recommendations (2008) and further developments. Eur J Prev Cardiol 2012;19:32-40.

49 Ponikowski P, Voors AA, Anker SD, Bueno H, Cleland JG, Coats AJ, Falk V, González-Juanatey JR, Harjola VP, Jankowska EA, et al. 2016 ESC Guidelines for the diagnosis and treatment of acute and chronic heart failure: the Task Force for the diagnosis and treatment of acute and chronic heart failure of the European Society of Cardiology (ESC). Developed with the special contribution of the Heart Failure Association (HFA) of the ESC. Eur J Heart Fail 2016;18: 891-975.

50 Kitzman DW, Groban L. Exercise intolerance. Heart Fail Clin 2008;4: 99-115.

51 Guazzi M, Myers J, Peberdy MA, Bensimhon D, Chase P, Arena R. Exercise oscillatory breathing in diastolic heart failure: prevalence and prognostic insights. Eur Heart $J$ 2008;29:2751-2759.

52 Shafiq A, Brawner CA, Aldred HA, Lewis B, Williams CT, Tita C, Schairer JR, Ehrman JK, Velez M, Selektor Y, et al. Prognostic value of cardiopulmonary exercise testing in heart failure with preserved ejection fraction: the Henry Ford HosplTal CardioPulmonary EXercise Testing (FIT-CPX) project. Am Heart J 2016;174:167-172

53 Guazzi M, Myers J, Arena R. Cardiopulmonary exercise testing in the clinical and prognostic assessment of diastolic heart failure. $J \mathrm{Am}$ Coll Cardiol 2005;46:1883-1890.
54 Murdock DK, Lawless CE, Loeb HS, Scanlon PJ, Pifarré R. The effect of heart transplantation on Cheyne-Stokes respiration associated with congestive heart failure. J Heart Transplant 1986;5:336-337.

55 Ribeiro JP, Knutzen A, Rocco MB, Hartley LH, Colucci WS. Periodic breathing during exercise in severe heart failure. Reversal with milrinone or cardiac transplantation. Chest 1987;92:555-556.

56 Tomcsányi J, Karlócai K, Papp L. Disappearance of periodic breathing after heart operations. J Thorac Cardiovasc Surg 1994;107:317-318.

57 Arzt M, Schulz M, Wensel R, Montalvàn S, Blumberg FC, Riegger GA, Pfeifer M. Nocturnal continuous positive airway pressure improves ventilatory efficiency during exercise in patients with chronic heart failure. Chest 2005;127:794-802.

58 Kazimierczak A, Krzyżanowski K, Wierzbowski R, Ryczek R, Smurzyński P, Michałkiewicz D, Orski Z, Gielerak G. Resolution of exercise oscillatory ventilation with adaptive servoventilation in patients with chronic heart failure and Cheyne-Stokes respiration: preliminary study. Kardiol Pol 2011;69:1266-1271.

59 Zurek M, Corrà U, Piepoli MF, Binder RK, Saner H, Schmid JP. Exercise training reverses exertional oscillatory ventilation in heart failure patients. Eur Respir J 2012;40:1238-1244.

60 Corrà U, Pistono M, Mezzani A, Braghiroli A, Giordano A, Lanfranchi P, Bosimini E, Gnemmi M, Giannuzzi P. Sleep and exertional periodic breathing in chronic heart failure: prognostic importance and interdependence. Circulation 2006;113:44-50. 